\title{
A Simple Parameterization Coupling the Convective Daytime Boundary Layer and Fair-Weather Cumuli
}

\author{
LARRY K. BERG \\ Pacific Northwest National Laboratory, Richland, Washington \\ Roland B. STULL \\ Atmospheric Science Programme, Department of Earth and Ocean Sciences, University of British Columbia, Vancouver, \\ British Columbia, Canada
}

(Manuscript received 23 February 2004, in final form 12 July 2004)

\begin{abstract}
A new parameterization for boundary layer cumulus clouds, called the cumulus potential (CuP) scheme, is introduced. This scheme uses joint probability density functions (JPDFs) of virtual potential temperature $\left(\theta_{v}\right)$ and water-vapor mixing ratio $(r)$, as well as the mean vertical profiles of $\theta_{v}$, to predict the amount and size distribution of boundary layer cloud cover. This model considers the diversity of air parcels over a heterogeneous surface, and recognizes that some parcels rise above their lifting condensation level to become cumulus, while other parcels might rise as noncloud updrafts. This model has several unique features: 1) cloud cover is determined from the boundary layer JPDF of $\theta_{v}$ versus $r, 2$ ) clear and cloudy thermals are allowed to coexist at the same altitude, and 3) a range of cloud-base heights, cloud-top heights, and cloud thicknesses are predicted within any one cloud field, as observed.

Using data from Boundary Layer Experiment 1996 and a model intercomparsion study using large eddy simulation (LES) based on Barbados Oceanographic and Meteorological Experiment (BOMEX), it is shown that the $\mathrm{CuP}$ model does a good job predicting cloud-base height and cloud-top height. The model also shows promise in predicting cloud cover, and is found to give better cloud-cover estimates than three other cumulus parameterizations: one based on relative humidity, a statistical scheme based on the saturation deficit, and a slab model.
\end{abstract}

\section{Introduction}

Numerical models of the atmosphere have been a boon to operational meteorologists since the introduction of the first routine numerical weather forecasts in the 1950s (Charney et al. 1950). While the complexity of numerical models has increased greatly since then, these models still represent the atmosphere at discrete grid points (Richardson 1922), rather than as a continuous fluid. Because of the discrete nature of these models, parameterizations are needed to account for processes that occur on spatial scales smaller than the model grid cell. For example, boundary layer turbulence and cumulus cloud diameters occur at scales smaller than the typical horizontal grid spacing used in global climate and weather forecast models.

Statistical parameterizations of cloud cover, the motivation of this work, are commonly used in operational

Corresponding author address: Dr. Larry K. Berg, Pacific National Lab, K9-30, Richland, WA 98325.

E-mail: larry.berg@pnl.gov models to explicitly predict the total cloud cover, which is critical for calculating the surface energy balance. Using a relative humidity threshold to predict cloud cover is a simple example. Sommeria and Deardorff (1977) proposed a statistical scheme based on the normalized saturation deficit. They assumed a Gaussian distribution of humidity and integrated a fraction of that distribution to obtain cloud cover. Mellor (1977) and Cuijpers and Bechtold (1995) further developed the scheme of Sommeria and Deardorff. Other authors (e.g., Slingo 1987; Sundqvist 1978; Smith 1990; Xu and Krueger 1991; Roeckner et al. 1996; Bony and Emanuel 2001) have proposed methods to estimate cloud cover based on a distribution of relative humidity within a model grid cell. Recent work by Lock et al. (2000) and Lappen and Randall (2001) has attempted to couple the parameterizations of the clear boundary layer and the clouds. In their model, the fractional coverage of updrafts is related to the skewness of the vertical velocity distribution. Cheinet (2003) presented a scheme similar to the cumulus potential (CuP) scheme, but specified the size of their joint probability density functions (JPDFs) from similarity relations, while Bretherton et 


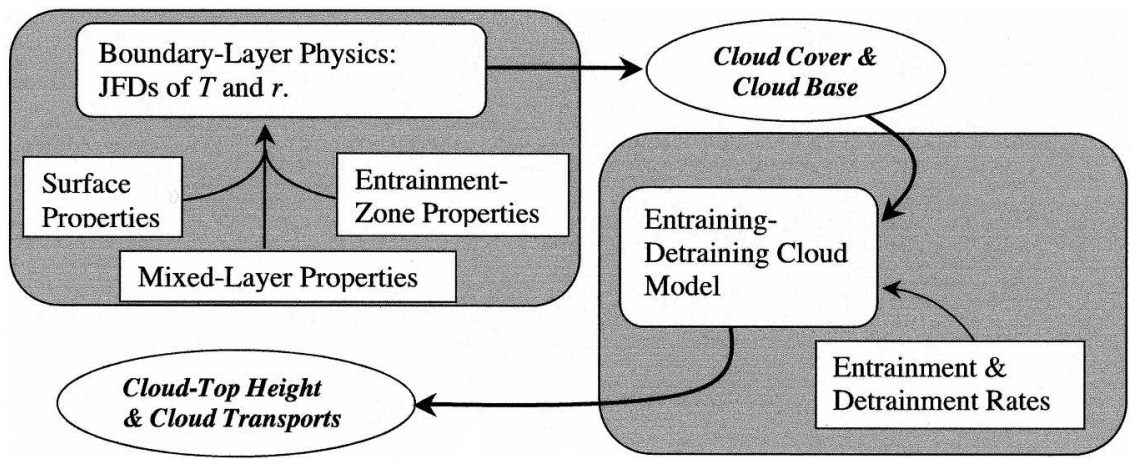

FIG. 1. CuP scheme flow diagram. Shading represents the two main modules: boundary layer physics, and processes in the cloud. Squares indicate input into the two modules. Ovals indicate output from the scheme.

al. (2004) used distributions of vertical velocity to determine the cloud cover. Neggers et al. (2002) developed a scheme that is based on a distribution of parcels generated from large eddy simulation (LES). Wetzel (1990) has also suggested a parcel method to determine the boundary layer cloud cover, but used ad hoc temperature perturbations.

Other parameterizations have been created specifically to study shallow cumulus. Malkus $(1954,1958)$ divided the trade wind boundary layer into cloud and subcloud layers. Betts (1973, 1976) studied boundary layer cumuli in the Tropics. Albrecht (1979) developed a model for trade wind cumuli using a mass-flux parameterization, a well-mixed subcloud layer, and a cloud layer. Albrecht (1981) and Wang and Albrecht (1986, 1990) extended the work of Albrecht (1979) to maritime stratocumuli-topped boundary layers. They used their models to study the breakup of stratocumuli. However, Bretherton (1993) showed that these studies were very sensitive to the chosen values of free parameters. Haiden (1996) has generalized the Albrecht (1981) expressions for cloud cover.

In this manuscript a new statistical cloud parameterization, based on the potential of boundary layer parcels to form clouds, will be presented. This $\mathrm{CuP}$ scheme is one way of coupling the clear and cloudy portions of the boundary layer. The CuP scheme is composed of two independent modules, which are described in the next section: one to represent boundary layer physics and one to represent boundary layer clouds. Boundary layer physics is represented with JPDFs of virtual potential temperature $\left(\theta_{v}\right)$ versus water-vapor mixing ratio ( $r$ ) (Berg and Stull 2004). Clouds in the scheme are represented with an entraining-detraining cloud model. This scheme has several features: 1) cloud cover is determined by properties of the convective boundary layer, 2) a range of cloud-top heights, cloud-base heights, and cloud thicknesses are predicted, and 3) a unique layer is predicted that consists of both clear and cloudy updrafts, as is observed. The CuP parameterization is similar to the parameterizations proposed by
Sommeria and Deardorff (1977) and Mellor (1977), who also used JPDFs to predict cloud cover, but there are some important differences. First, the CuP parameterization uses tilted JPDFs that include a correlation between $\theta_{v}$ and $r$ to determine if a parcel in the clear layer will rise and form a cloud, while the method of Sommeria and Deardorff (1977) used nontilted JPDFs of saturation deficit to determine cloud cover. Second, the CuP JPDFs represent processes below the clouds, while the distributions of Sommeria and Deardorff (1977) represent processes in the cloud layer.

This manuscript is organized as follows: The new scheme will be described in section 2 . The calibration of entrainment and detrainment rates using data from Barbados Oceanographic and Meteorological Experiment (BOMEX) will be described in section 3. Next, Boundary Layer Experiment 1996 (BLX96), the field campaign used to verify the scheme, will be described in section 4 , and cloud predictions by the $\mathrm{CuP}$ model and the alternative methods will be shown in section 5 .

\section{A new scheme: The cumuli potential model}

The CuP parameterization consists of two independent modules: one represents boundary layer physics, the other represents clouds (Fig. 1). The boundary layer physics are represented using JPDFs of virtual potential temperature $\left(\theta_{v}\right)$ versus water-vapor mixing ratio $(r)$. These JPDFs provide a compact way to represent the net effects of boundary layer turbulence, and to determine the fraction of boundary layer parcels that will form clouds. Once clouds form, they are represented using an entraining-detraining cloud model.

\section{a. Boundary layer physics module}

The CuP scheme examines each parcel in the boundary layer over a heterogeneous surface, determines if that parcel will rise, and then, if the parcel does rise, determines if that parcel will rise high enough to form a cloud, as illustrated in Fig. 2. Conceptually, each par- 


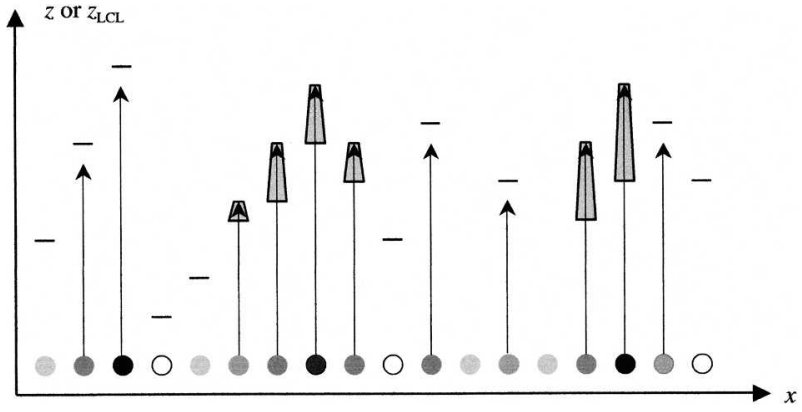

FIG. 2. Sketch of a group of near-surface boundary layer parcels over a heterogeneous surface. The shading of each parcel represents its temperature (darker are warmer). Dashes aloft represent the $z_{\mathrm{LCL}}$ for each parcel. The arrows indicate how high each parcel will rise. Those parcels that rise above their $z_{\mathrm{LCL}}$ are marked with a shaded area. Some parcels are too cool to rise at all.

cel is much smaller than the typical cloud, so that a number of parcels are required to form a cloud. Those parcels that are more buoyant than the environment will rise. The rising parcels are assumed to mix with the environment as they rise through the mixed layer. For simplicity, the entrainment rate below cloud base is assumed to be the same as that used in the cloud model (which is defined in the next subsection). The detrainment rate below cloud base was assumed to be zero, because mixtures of parcel and environmental air will always be positively buoyant and will most likely continue to rise. In practice, the scheme was not sensitive to the entrainment and detrainment rates used in the mixed layer because the thermodynamic properties of the thermals are not much different than the mixedlayer mean $\theta_{v}$ and $r$. The most buoyant parcels should rise the highest. However, if a warm parcel is also dry, it still may not reach its height of the lifting condensation level $\left(z_{\mathrm{LCL}}\right.$, which is determined from the parcel's temperature and water-vapor mixing ratio), so it will remain part of a clear-air updraft. A less buoyant parcel, but one that is still more buoyant than the environment, might not rise as high, but might be more moist so that it rises to its individual $z_{\mathrm{LCL}}$ and the water vapor in the parcel will condense. The parcel will continue to rise as a cloudy parcel. Thus, the cloud cover is related to the fraction of boundary layer parcels that reach their $z_{\mathrm{LCL}}$. As shown in Fig. 2, there is a range of both parcel $z_{\mathrm{LCL}}$ values and heights at which the cloudy parcels stop rising. There is also an altitude region where some rising parcels are cloudy and some parcels are clear. The variation of cumulus cloud-base heights over heterogeneous land surfaces is an everyday occurrence as reported by both general- and research-aviation pilots flying near cloud base, even though the same cloud fields, as seen by human observers on the ground, appear to have a uniform, single cloud-base altitude.

The virtual potential temperature $\left(\theta_{v}\right)$ and moisture of these surface-layer parcels can be combined to form a joint frequency distribution (JFD). That JFD can be compared to the mean environmental profile of $\theta_{v}$ and parcels that are more buoyant than the environment will rise. To apply the CuP scheme, the size and shape of the JFD must be determined. Berg and Stull (2004) developed a physically based parameterization that treats the distribution of $\theta_{v}$ and $r$ in the boundary layer as mixing diagram, with the distribution of parcels reaching along mixing lines connecting the boundary layer mean values to both the surface and the entrainment zone properties (Fig. 3). They used these mixing lines to define the slopes of two new axes that they used to fit a JPDF to observed JFDs. The slope of the surface axis was parameterized in terms of sensible and latent heat fluxes, and the slope of the entrainment-zone axis was determined by the change of $\theta_{v}$ and $r$ through the entrainment zone. Similarity relationships were derived to express the spread of the JPDFs along each axis. They found that this new method worked better than one based on surface-layer processes (Schrieber et al. 1996) and worked as well as a statistical scheme (Wyngaard and Moeng 1992).

\section{b. Cloud module}

In the $\mathrm{CuP}$ scheme, the cloud-base properties are computed from individual $\theta_{v}$ and $r$ of the rising parcels determined in the boundary layer physics module. A simple entraining-detraining cloud model, in which mixing between the cloud and environment occurs at a constant rate as the cloud rises, is used to represent clouds (e.g., Malkus 1958; Simpson and Wiggert 1969; Betts 1975, 1976). In this type of model, the cloud mass flux associated with a field of cumuli is defined as

$$
\frac{\partial M}{\partial z}=M(\varepsilon-\delta)
$$

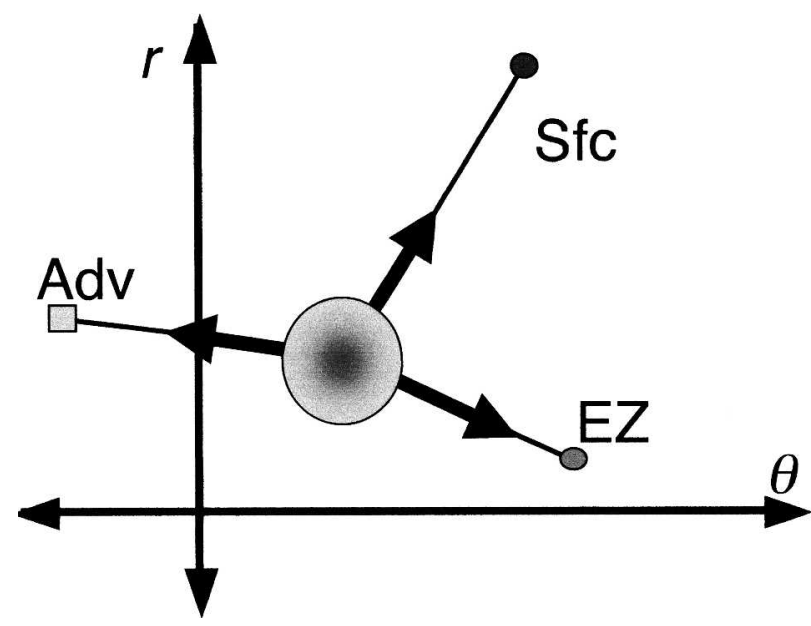

FIG. 3. The $\theta$ vs $r$ mixing diagram. The large circle represents the mixed-layer mean, the small circles represent the surface (Sfc) and entrainment-zone properties (EZ), and the square represents the advection (Adv). The large arrows indicate the "direction" that the different processes pull on the mixed-layer mean (after Berg and Stull 2004). 
where $M$ is the cloud mass flux, $\varepsilon$ is the fractional entrainment rate, and $\delta$ is the fraction detrainment rate. The thermodynamic properties of the cloud population also change as a function of height, such that

$$
\frac{\partial M \psi}{\partial z}=M\left(\varepsilon \bar{\psi}-\delta \psi_{c}\right)
$$

where $\psi$ is the thermodynamic property of interest, $\bar{\psi}$ is the environmental average of $\psi$, and $\psi_{c}$ is the in-cloud value of $\psi$. The values of $\varepsilon$ and $\delta$ that are used with the CuP scheme were selected to be $\varepsilon=1.0 \times 10^{-3} \mathrm{~m}^{-1}$ and $\delta=3.0 \times 10^{-3} \mathrm{~m}^{-1}$. These values are consistent with estimates found using LES of the trade wind boundary layer for a population of cumuli (Siebesma and Cuijpers 1995; Siebesma and Holtslag 1996). We desire to apply the values of $\varepsilon$ and $\delta$ to families of cloudy parcels, where a family of parcels is defined as parcels from the same bin of the JPDF. If we assume $N$ total cloudy parcels in the family, then (1) can be rewritten for a family of parcels as

$$
\begin{array}{r}
\frac{\partial\left(M_{f, 1}+M_{f, 2}+\cdots+M_{f, N}\right)}{\partial z}=\left[M_{f, 1}\left(\varepsilon_{1}-\delta_{1}\right)\right. \\
\left.+M_{f, 2}\left(\varepsilon_{2}-\delta_{2}\right)+\cdots+M_{f, N}\left(\varepsilon_{N}-\delta_{N}\right)\right],
\end{array}
$$

where the subscript $f$ indicates a parcel family, and the numbers indicate a specific parcel within the family. If we assume that $\varepsilon$ and $\delta$ are the same for all parcels in the family, then $\varepsilon$ and $\delta$ can be factored out of (3), and the values suggested by Siebesma and Cuijpers (1995) and Siebesma and Holtslag (1996) for a population of cumuli are applied to a family of parcels that represent a large portion of the cloud field. Using data from BLX96, the five parcel families that contributed the most to the number of cloudy parcels accounted for over $90 \%$ of all the cloudy parcels in all but 4 of 22 cases studied. These rates are also consistent with an entrainment rate of $1 \times 10^{-3} \mathrm{~m}^{-1}$ determined by Barnes et al. (1996) for individual cumuli. The use of a simple model ignores several processes that maybe important in the life cycle of real clouds, including different entrainment and detrainment rates for various parcels, or radiative or evaporative cooling at cloud top that can lead to the presence of downdrafts in clouds.

Cloud-top height predicted by the entrainingdetraining cloud model is a function of $\varepsilon$ and $\delta$ rates and the method used to stop the rising parcels. Two methods were tested to stop parcels, either the level at which a parcel reaches its level of neutral buoyancy (LNB), or the level at which all the parcel's convective available potential energy (CAPE) is dissipated. CAPE can defined as

$$
\mathrm{CAPE}=\frac{g}{\theta_{v, \text { env }}} \int_{z_{1}}^{z_{2}}\left[\theta_{v, \text { parcel }}(z)-\theta_{v, \text { env }}(z)\right] d z,
$$

where $g$ is the acceleration due to gravity, $\theta_{v \text {, env }}$ is the $\theta_{v}$ of the environment, $\theta_{v \text {, parcel }}$ is the $\theta_{v}$ of the parcel, and $z_{2}$ and $z_{1}$ are the top and bottom of the layer of interest. When entraining-detraining parcels are allowed to rise to their LNB, the CuP-predicted cloud cover is too small and the clouds are generally very thin. CAPE is a more realistic indicator to determine the altitude at which parcels stop rising, and will be used here. The exact cloud-top height is also a function of the entrainment and detrainment rates, because clouds that entrain less environmental air remain buoyant to a greater height and should rise higher. Alternatively, one could derive an expression that explicitly predicts the parcel's vertical velocity (e.g., Bretherton et al. 2004).

The arguments of the previous subsections tell us about the birth rate of new clouds triggered by active thermals. Let $\alpha_{\text {active }}$ be the portion of cloud cover still driven by thermal updrafts, which can be estimated as the fraction of cloudy parcels determined from the JPDF and the $\theta_{v}$ profile in the boundary layer module. The value of $\alpha_{\text {active }}$ is similar to the cloud-core fraction obtained from LES, which is defined as the fraction of grid points that are positively buoyant and cloudy. A difference between these two values occurs if a negatively buoyant parcel's CAPE is greater than 0 (which would contribute to $\alpha_{\text {active }}$ but would not be defined as cloud core) at some level. Once a cloud exists, it might have a lifetime independent of the thermal lifetime (defined as $z_{i} / w_{*}$, where $z_{i}$ is the mixed layer depth and $w_{*}$ is the Deardorff convective velocity scale). These lingering clouds add to the cloud cover (Albrecht 1981; Stull 1985; Haiden 1996). A prognostic equation for the total cloud cover, in which the cloud death rate is modeled as an exponential decay process, and explicitly includes the cloud birth rate, can be written as

$$
\frac{d \alpha_{\text {cloud }}}{d t}=\frac{\alpha_{\text {active }}}{t_{\text {active }}}-\frac{\alpha_{\text {cloud }}}{\tau_{\text {cloud }}},
$$

where $\alpha_{\text {cloud }}$ is the cloud-cover fraction at some time, $t$. An active cloud time scale can be defined as $t_{\text {active }}=$ $z_{\text {top }} / w_{*}$, where $z_{\text {top }}$ is the average cloud-top height. This definition of $t_{\text {active }}$ is supported by the work of Neggers et al. (2002), who determined from LES that the average cloud time scale for cumuli during BOMEX was nearly independent of the cloud size. One could argue that the cloud updraft velocity scale should be used in the definition of $t_{\text {active }}$, rather than $w_{*}$. But, definitions of cloud updraft velocity scales that have appeared in the literate require either more free parameters (Simpson and Wiggert 1969), or do not allow negative values of CAPE (Grant and Brown 1999). Using $w_{*}$ is not problematic when the $\mathrm{CuP}$ scheme is applied to the BLX96 data, because only relatively thin cumuli were encountered, but it could be an issue in situations with more vigorous cumuli. The cloud lifetime $\left(\tau_{\text {cloud }}\right)$ is similar to that derived by Albrecht (1981) and Haiden (1996), in which they modeled the cloud total water as an exponential decay process. They defined $\tau_{\text {cloud }}$ to be a function of the cloud liquid water, and the saturation 
deficit of the environment, but their definitions do not explicitly account for changes of either with height. A slightly modified version of $\tau_{\text {cloud }}$ is proposed here, based on the integrated cloud liquid water and integrated saturation deficit, such that

$$
\tau_{\text {cloud }}=t_{*} \ln \left[1+(1+\gamma) \frac{\int l_{\text {cloud }} d z}{\int \delta r_{s} d z}\right] \text {, }
$$

where $t_{*}$ is the boundary layer time scale $\left(w_{*} / z_{i}\right), l_{\text {cloud }}$ is the cloud liquid water, $\delta r_{s}$ is the saturation deficit of the environment $\left(r_{s, \text { env }}-r_{\text {env }}\right)$, and $\gamma=\left(L / C_{p}\right)\left(\partial \bar{r}_{s, \text { env }} /\right.$ $\left.\partial \bar{T}_{\text {env }}\right)$. The integrated values of $l_{\text {cloud }}$ and $\delta r_{s}$ were computed using the mean $\theta_{v}$ and $r$ profiles and results from the cloud model. The value of $\gamma$ was defined using the thermodynamic conditions at the cloud base and is assumed to be constant with height, which is a fair approximation for shallow cumuli.

Values of $\tau_{\text {cloud }}, \alpha_{\text {active }}$, and $t_{\text {active }}$ were computed for each BLX96 sounding. The value of $\tau_{\text {cloud }}$ could vary from cloud to cloud, making the application of (5) more difficult. However, during BLX96, the value of $\int l_{\text {cloud }}$ $d z / \int \delta r_{s} d z$ and hence the value of $\tau_{\text {cloud }}$ varied little from cloud to cloud so that an average value of $\tau_{\text {cloud }}$ is used in this study. The variables $\tau_{\text {cloud }}, \alpha_{\text {active }}$, and $t_{\text {active }}$ are rarely constant with time and (5) becomes much more difficult to solve analytically. Runge-Kutta methods were used to solve (5) assuming that $\tau_{\text {cloud }}, \alpha_{\text {active }}$, and $t_{\text {active }}$ change linearly with time between soundings measured during BLX96.

Equation (5) is similar to that used by Albrecht (1981) and improved by Haiden (1996), but the assumption of quasi-stationary of the cloud field has been relaxed. In the steady-state case (5) predicts the cloud cover to be, $\alpha_{\text {cloud }}=\left(\tau_{\text {cloud }} \alpha_{\text {active }}\right) / t_{\text {active. }}$. In this situation, the cloud cover is less than $\alpha_{\text {active }}$ when $\tau_{\text {cloud }}$ is smaller than $t_{\text {active }}$. This could occur when the ambient air in the cloud layer is dry, or when $l_{\text {cloud }}$ is small and the clouds evaporate quickly.

\section{Calibration of entrainment and detrainment rates against BOMEX}

Several modeling studies (Siebesma and Cuijpers 1995; Siebesma and Holtslag 1996; Siebesma et al. 2003) have used LES to estimate the values of $\varepsilon$ and $\delta$. These studies have been based on observations from phase 3 (22 to 23 June 1969) of BOMEX (Holland and Rasmusson 1973). The results of these studies will be used to calibrate values of $\varepsilon$ and $\delta$ required by the $\mathrm{CuP}$ scheme because of the lack of observations in the cloud layer during BLX96. The observed mean profiles, measured surface fluxes, along with LES estimates of entrainment zone fluxes were obtained from Siebesma et al. (2003). These variables were used to create a JPDF

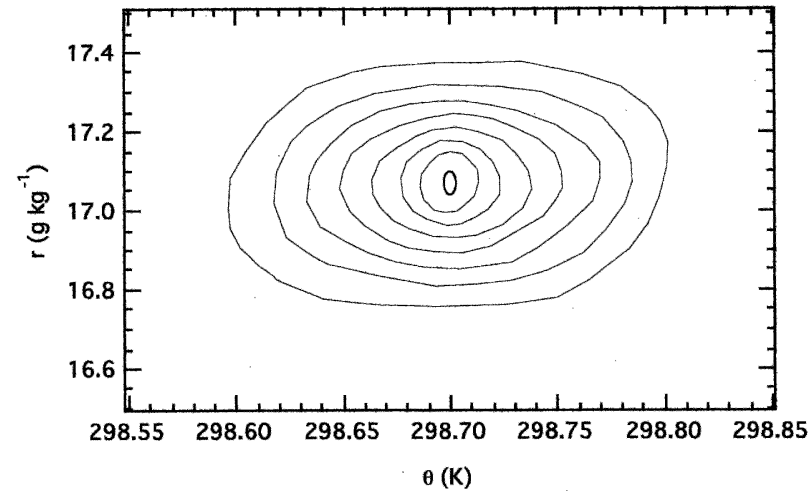

FIG. 4. Parameterized JPDF for the BOMEX case. The first contour marks a normalized frequency of 0.02 , and the contour interval is 0.02 .

(Fig. 4) using the parameterizations introduced by Berg and Stull (2004). The mean profiles of $\theta_{v}$ and $r$, and surface fluxes during BOMEX were approximately steady state, and only one value of cloud cover is obtained for this comparison study. Values of the variables needed to drive the CuP scheme for the BOMEX comparison can be found in the appendix.

The cloud-base and cloud-top heights predicted by the $\mathrm{CuP}$ parameterization using $\varepsilon=1.0 \times 10^{-3}$ and $\delta=$ $3.0 \times 10^{-3}$ and LES-predicted values are similar (Fig. $5)$. There is also good agreement in the general shape of the LES cloud cover and CuP-predicted $\alpha_{\text {active }}$ as a function of height. There is also agreement in the highest cloud tops predicted by the CuP scheme, which stops the highest parcels near an altitude of $1.9 \mathrm{~km}$, and the LES, which stops most of the clouds near an altitude of $2 \mathrm{~km}$. The good agreement between the LES and $\mathrm{CuP}$ cloud heights suggests that the choice of $\varepsilon$ and $\delta$ used in the $\mathrm{CuP}$ scheme is appropriate. But, von Salzen and McFarlane (2002) point out that cloud tops on 22 and 23 June were likely higher than reported by LES. An additional sensitivity analysis was conducted to evaluate the sensitivity of the CuP scheme to changes in $\varepsilon$. The value of $\varepsilon$ was allowed to range from $5 \times 10^{-4}$ to $2 \times 10^{-3} \mathrm{~m}^{-1}$, while $\delta$ was held constant (Fig. 6). When $\varepsilon$ was equal to $5 \times 10^{-4} \mathrm{~m}^{-1}$ the parcels reach as high as $2.2 \mathrm{~km}$, but when $\varepsilon$ was equal to $2 \times 10^{-3} \mathrm{~m}^{-1}$ cloudy parcels only reach as high as $1.7 \mathrm{~km}$. These height differences are fairly large and give us confidence that the values of $\varepsilon$ and $\delta$ are appropriate. The total cloud cover was not sensitive to changes in $\varepsilon$ and $\delta$ because changing these variables also changed the cloud time scales. The value of $\alpha_{\text {active }}$ shown in Fig. 6 increases with increasing $\varepsilon$ because $\delta$ was held constant. In cases with a small value of $\varepsilon$ relative to $\delta$, there is a net detrainment of mass out of the clouds leading to a shrinking of $\alpha_{\text {active }}$, as $\varepsilon$ increases, the net detrainment of mass out of the clouds is reduced and $\alpha_{\text {active }}$ is enhanced.

Unfortunately, there are large differences in LES- 

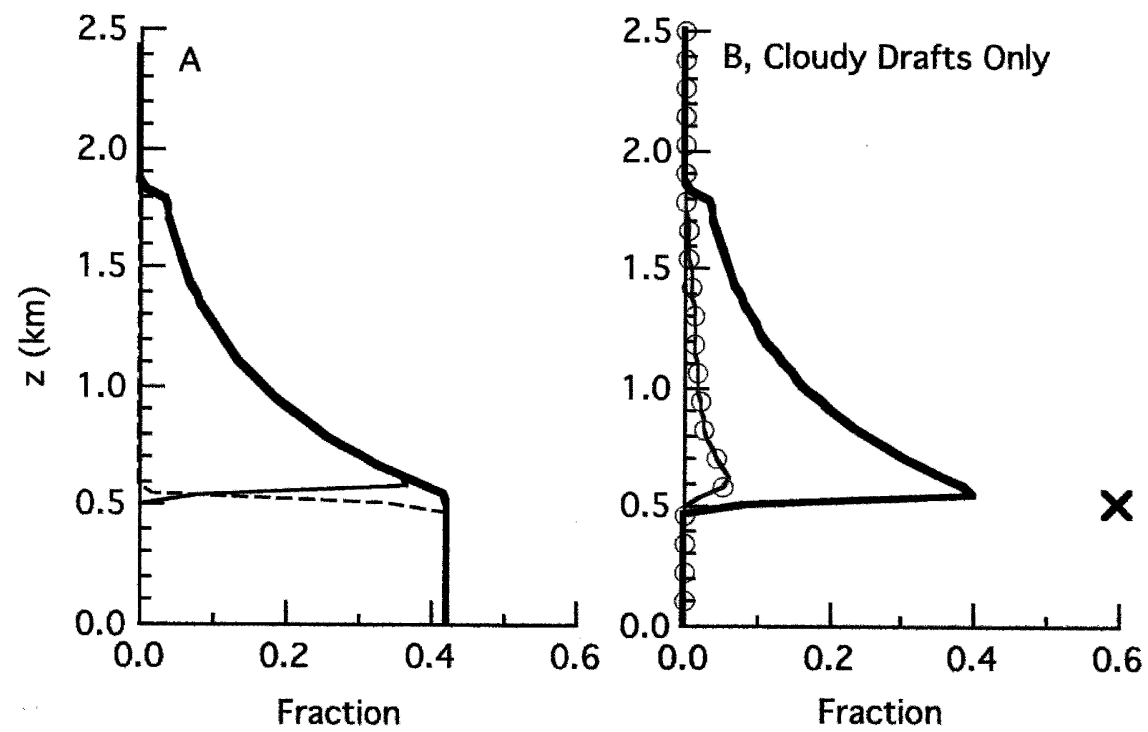

FIG. 5. (a) Total instantaneous updraft fraction (thick line), active cloudy updraft fraction $\left(\alpha_{\text {active }}\right)$ (thin line) and clear updraft fraction (dashed line) predicted by the CuP scheme for BOMEX. (b) Active cloudy updraft fraction $\left(\alpha_{\text {active }}\right)$ predicted by the CuP scheme (thick line), LES cloud cover (line with circles) of Siebesma et al. (2003), and average BOMEX cloud cover $(\times)$ reported by Delnore (1972).

predicted total cloud cover (defined as the vertical projection of clouds onto the surface), which was about $12 \%$, and the CuP predicted total cloud cover [from (5)], which was about $35 \%$. These estimates of total cloud cover should not be confused with the results presented in Fig. 5, which for the LES represents the fraction of the model grid cells at any level that are cloudy and positively buoyant, and for which the $\mathrm{CuP}$ represents $\alpha_{\text {active }}$. The total cloud cover simulated by LES is likely larger than that reported in Fig. 5 because of the tilting of clouds by the mean wind, and because some portions of clouds are not positively buoyant, while the total cloud cover simulated by the $\mathrm{CuP}$ scheme is smaller than the active cloudy updraft fraction reported in Fig. 5 because of the application of (5) to determine the total cloud cover. A sensitivity analysis for BOMEX shows that the CuP-predicted total cloud cover is not very sensitive to the values of $\varepsilon$ and $\delta$, because increasing $\varepsilon$ tends to reduce both $t_{\text {active }}$ (because of a reduction in cloud top height) in (6), and $\tau_{\text {cloud }}$ (because of a reduction in $l_{\text {cloud }}$ from increased mixing and an increase in $\delta r_{s}$ due to the change in cloud-top height) in (6). In addition, allowing $\varepsilon$ and $\delta$ to vary between parcels could lead to changes in the cloud cover as a function of height. Although there are some uncertainties, BOMEX is useful for calibration of $\varepsilon$ and $\delta$ to yield the proper cloud-base and cloud-top heights even with the large differences in predicted cloud cover. There is also uncertainty in the observed cloud amount during BOMEX. The average observed cloud amount reported by Delnore (1972), based on bridge reports from the research ships, was 0.6 , much larger than the $12 \%$ predicted by LES. This amount was for the entire phase 3 of BOMEX (20 June to 1 August), so individual days might have had more or less cloud cover. Nitta (1975) shows a surface weather map for 1200 UTC 22 June 1969 with overcast conditions at the center of the BOMEX ship array and cloud cover of 0.1 east of the BOMEX ships, so it is difficult to quantify the actual cloud cover.

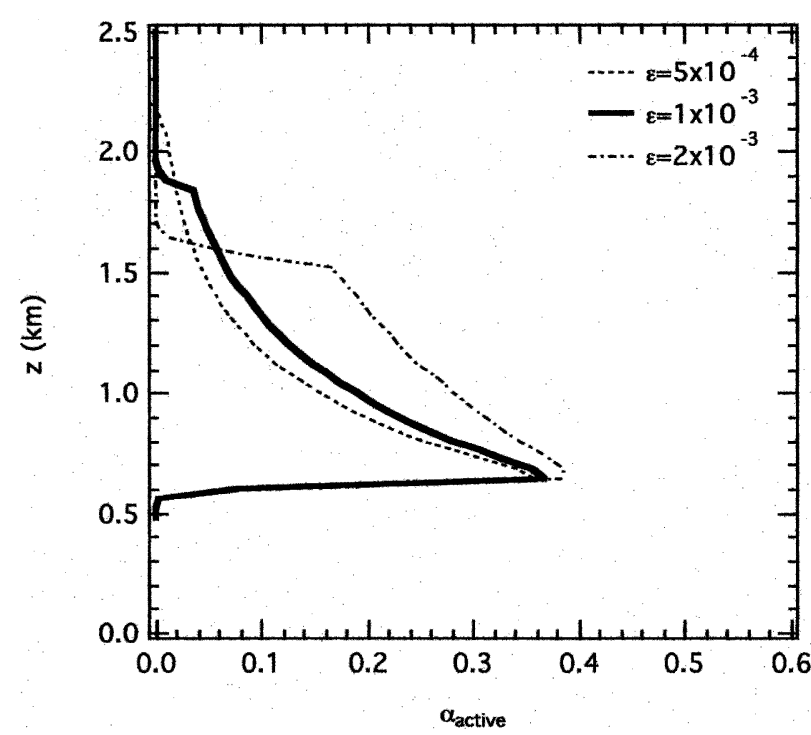

FIG. 6. Active cloudy updraft fraction $\left(\alpha_{\text {active }}\right)$ computed using the CuP scheme for BOMEX with $\varepsilon$ equal to $5 \times 10^{-4}$ (dotted line), $1 \times 10^{-3}$ (solid line), and $2 \times 10^{-3} \mathrm{~m}^{-1}$ (dot-dashed line). 


\section{Boundary Layer Experiment 1996}

\section{a. General description}

BLX96 was conducted between 15 July and 13 August 1996 over regions within the U.S. Department of Energy's Atmospheric Radiation Measurement (ARM) Southern Great Plains (SGP) Clouds and Radiation Test bed (CART; Stokes and Schwartz 1994). This region includes parts of north-central Oklahoma and south-central Kansas. Details of BLX96 were reported by Stull et al. (1997) and Berg et al. (1997) and can be found at http://weather2.eos.ubc.ca/BLX96/. A total of twelve research flights were flown during BLX96. Each flight started between 1000 and 1030 local standard time (LST), and lasted 4 to $4.5 \mathrm{~h}$. Only ten flights were used for this study: 15, 16, 22, 23, 25, 27, 28, and 31 July and 2 and 13 August. On 16 July, the second half of the pattern was excluded because the measured moisture flux was suspect during the last near-surface leg (Berg 2002).

Slant ascent/descent legs were flown 3 times during each flight, near the start, middle and end. These flights were processed to obtain average soundings with $20-\mathrm{m}$ vertical resolution. Each slant sounding reached from near the surface to above cloud top and then back to the surface, and the up-down pair were averaged together. The final sounding of the day was flown from near the surface to above cloud top.

\section{b. Cloud observations}

Two methods for measuring cloud cover were used during BLX96: radiometric and manual. An upwardlooking Epply precision spectral pyranometer on the aircraft showed large differences between measurements made inside and outside cloud shadows. A threshold value of $575 \mathrm{~W} \mathrm{~m}^{-2}$ was applied to the unfiltered pyranometer time series to determine when the aircraft passed through a cloud shadow (Ek and Mahrt 1991). The estimated cloud cover was defined as the fraction of the whole leg that was within cloud shadows. The pyranometer-measured cloud cover was insensitive to the threshold chosen, for thresholds between 375 and $775 \mathrm{~W} \mathrm{~m}^{-2}$.

The airborne scientist on each flight also made estimates of cloud cover based on the cloud shadows projected on the ground. Fortunately, the area under the flight tracks was divided by roads and fence lines into 800-m ( $1 / 2$ mile) sections, allowing for more accurate estimates of cloud cover. All of the manual estimates for a given flight leg were averaged together to give a leg average. The number of human observations logged during any given leg ranged from one to ten. The airborne scientists also logged cloud thickness of the cumuli in three ways: 1) estimating aspect ratio (cloud width to cloud height) visually, 2) logging cloud-base and cloud-top altitudes during ascent and descent slant aircraft soundings, and 3) via postflight inspection of footage from the forward-looking automatic video camera. The accuracy of both the radiometer and the human-observed cloud cover during BLX96 was discussed by Berg and Stull (2002), who showed that errors in the radiometer measured cloud-cover estimates are likely less than \pm 0.05 given 70 -km-long flight legs.

\section{Results for BLX96}

Soundings measured by the aircraft and parameterized JPDFs created using the methods of Berg and Stull (2004) were used to test the CuP scheme. The soundings used with the CuP scheme were linear fits by eye to individual pairs of soundings, for the first two sets of soundings flown each day, or the single sounding measured at the end of the flight pattern. Straight-line segments were constructed so that each sounding could have several layers over which observations changed in a nearly linear fashion. Parameterized JPDFs were constructed for a height of $0.5 z_{i}$. The height $0.5 z_{i}$ was chosen for height of the JPDFs because the thermals, some of which rise to form clouds, are readily apparent at that altitude, and the scatter in the standard deviations of the JPDFs was small. The parcels were allowed to entrain air from $0.5 z_{i}$ to the altitude at which they stopped or became clouds, at which point the cloud model was applied (section 2).

Integration of (5) is generally sensitive to the initial value of cloud cover, which was taken to be the cloud cover measured during the previous set of profiles. Estimates of cloud cover as a function of height were not made because cloud cover as a function of height was not measured. The values of $\alpha_{\text {active }}, t_{\text {active }}$, and $\tau_{\text {cloud }}$ were determined for each set of soundings, and are assumed to change linearly with time between soundings, which were separated in time by approximately $1.75 \mathrm{~h}$. One exception to the linear change assumption was made as follows: If $\alpha_{\text {active }}$ and $\tau_{\text {cloud }}$ were zero at one sounding and nonzero at another, then the nonzero value was used with no linear change. This was done because very small values of $\tau_{\text {cloud }}$ cause (5) to predict unrealistically large values of $\alpha_{\text {cloud }}$. In general, this assumption of a linear change may not be valid; however, the BLX96 flights occurred after the morning transition period, when the boundary layer is thick and changes relatively slowly with time. Such an assumption would not be required if the scheme is applied in an atmospheric model because the values of $\alpha_{\text {active, }} t_{\text {active }}$, and $\tau_{\text {cloud }}$ can be determined at each time step.

\section{a. Other published methods of predicting cloud fields}

In addition to cloud-cover, cloud-base height, and cloud-top height estimates made using the CuP scheme, estimates made using three other schemes will be shown for comparison: 1) the relative humidity-based scheme used in the ECHAM4 global climate model 
(Roeckner et al. 1996), 2) the classical statistical scheme suggested by Sommeria and Deardorff (1977), and 3) the scheme suggested by Albrecht (1981) for trade cumuli.

The parameterization used by Roeckner et al. (1996) for cloud cover is

$$
\alpha_{\text {cloud }}=1-\left(1-\frac{\mathrm{RH}-\mathrm{RH}_{\mathrm{cr}}}{1-\mathrm{RH}_{\mathrm{cr}}}\right)^{1 / 2},
$$

where $\mathrm{RH}$ is the relative humidity, and $\mathrm{RH}_{\mathrm{cr}}$ is a critical value of $\mathrm{RH}$. Here, $\mathrm{RH}_{\mathrm{cr}}$ is used to determine if air in the grid box is saturated, and is a function of height given by

$$
\mathrm{RH}_{\mathrm{cr}}=\mathrm{RH}_{0, \text { top }}+\left(\mathrm{RH}_{0, \mathrm{sfc}}-\mathrm{RH}_{0, \mathrm{top}}\right) \exp \left[1-\left(p_{\text {sfc }} p\right)^{4}\right]
$$

where $p_{\text {sfc }}$ is the surface pressure, and $p$ is the pressure. The values of $\mathrm{RH}_{0, \text { top }}$ and $\mathrm{RH}_{0, \mathrm{sfc}}$ represent the critical value of RH needed for cloud cover, and were equal to 0.6 and 0.99 , respectively. For example, at the surface, the exponential function in (8) becomes 1 , and $\mathrm{RH}_{\mathrm{cr}}=$ $\mathrm{RH}_{0, \mathrm{sfc}}$, so that $\mathrm{RH}$ must be greater than 0.99 for there to be cloud cover. Higher in the atmosphere, the second term becomes small, and an RH greater than 0.6 is needed for some cloud cover.

Sommeria and Deardorff (1977) postulated that cloud cover could be inferred using JPDFs of liquid water potential temperature $\left(\theta_{l}\right)$ versus humidity. From the JPDF, they calculated a normalized saturation deficit

$$
Q=\bar{s} / \sigma_{s}
$$

where $s$ is the saturation deficit, defined as $s=r_{\text {total }}-$ $r_{s}(T), r_{s}$ is the saturation mixing ratio, $r_{\text {total }}$ is the total water mixing ratio, and $\sigma_{s}$ is the standard deviation associated with the distribution of $s$. The value of $\sigma_{s}$ was assumed to be $0.8 \mathrm{~g} \mathrm{~kg}^{-1}$, as suggested by Siebesma et al. (2003). Assuming a Gaussian distribution to $s$, (9) can be integrated to give an estimate of the cloud cover

$$
\alpha_{\text {cloud }}=\frac{1}{2}\left[1+\operatorname{erf}\left(\frac{Q}{\sqrt{2}}\right)\right] .
$$

Albrecht (1981) suggests an expression for cloud cover based on the active lifetime and the decay time for clouds in the maritime boundary layer. He suggests

$$
\alpha_{\text {cloud }}=\frac{\tau}{\tau_{0}}\left(\frac{r_{\text {total }}-r_{s, \text { env }}}{r_{\text {total }}-r_{\text {env }}}\right),
$$

where $r_{s \text {,env }}$ is $r_{s}$ of the environment, $r_{\text {env }}$ is the $r$ of the environment, $\tau$ is the decay time constant, and $\tau_{0}$ is the time constant for the active phase of the clouds. Albrecht argues that $\tau \approx \tau_{0}$.

\section{b. Cloud cover}

The CuP scheme and the alternate methods described in section 5 a can be used to estimate the total cloud cover. Overall, the agreement between the $\mathrm{CuP}$ predicted cloud cover and cloud cover observed during individual flight legs is good but there is much scatter (Fig. 7). The mean absolute error is used to evaluate the performance of each scheme, and is defined as

$$
\text { err }=\frac{1}{N} \sum\left|\alpha_{\text {cloud,scheme }}-\alpha_{\text {cloud,obs }}\right|,
$$

where $\alpha_{\text {cloud,scheme }}$ is the cloud cover predicted by the scheme, $\alpha_{\text {cloud,obs }}$ is the observed cloud cover, and $N$ is the total number of observations. The $\mathrm{CuP}$ scheme had the smallest absolute error by a small margin, while the schemes of Roeckner et al. (1996) and Sommeria and Deardorff (1977) had the largest error (Table 1). The scatter in all of the methods indicates the difficulty in predicting small amounts of cloud cover. The mean absolute errors found using (12) are similar in magnitude to the measurement errors found by Berg and Stull (2002) (on the order of 0.05, compared to an error of 0.07 for the $\mathrm{CuP}$ scheme).

In addition to the calculations of absolute error, the bias of each scheme was computed. The methods of Albrecht (1981) and Sommeria and Deardorff (1977) have a bias of approximately -0.07 (Table 1 ). The method of Roeckner et al. (1996) overestimates the cloud cover, while the CuP scheme shows little bias. A least squares best fit was applied to the results from each scheme. The slope of the line fit to the $\mathrm{CuP}$ predicted cloud cover was 0.93 , and was the closest to 1.0 by a large margin (Table 1 ). The CuP scheme also had the highest sample correlation coefficient, 0.57 . Thus, of the four methods used, the CuP scheme has the smallest mean absolute error, the smallest bias, and the highest correlation.

There are a number of instances in which the CuP scheme does not do a good job predicting the cloud cover. These errors could be related to shortcomings in the CuP parameterization, which does not include all of the relevant physical processes. For example, the CuP scheme neglects a number of physical processes: radiative cooling at cloud top, evaporative cooling at cloud top, pressure-gradient forces, and subsidence. Our assumption of constant values of both $\varepsilon$ and $\delta$ (both in terms of height and using the same values for all parcels) could lead to errors in the predicted cloud cover. Work is currently underway to implement a stochastic cloud model into the CuP framework, which should address the issue. Other sources of error include errors in the linear soundings, which could increase or decrease the consumption of CAPE. Finally, this study has represented the interactions between the environment and the clouds as a one-way link, neglecting any interaction between the cumuli and their environment 


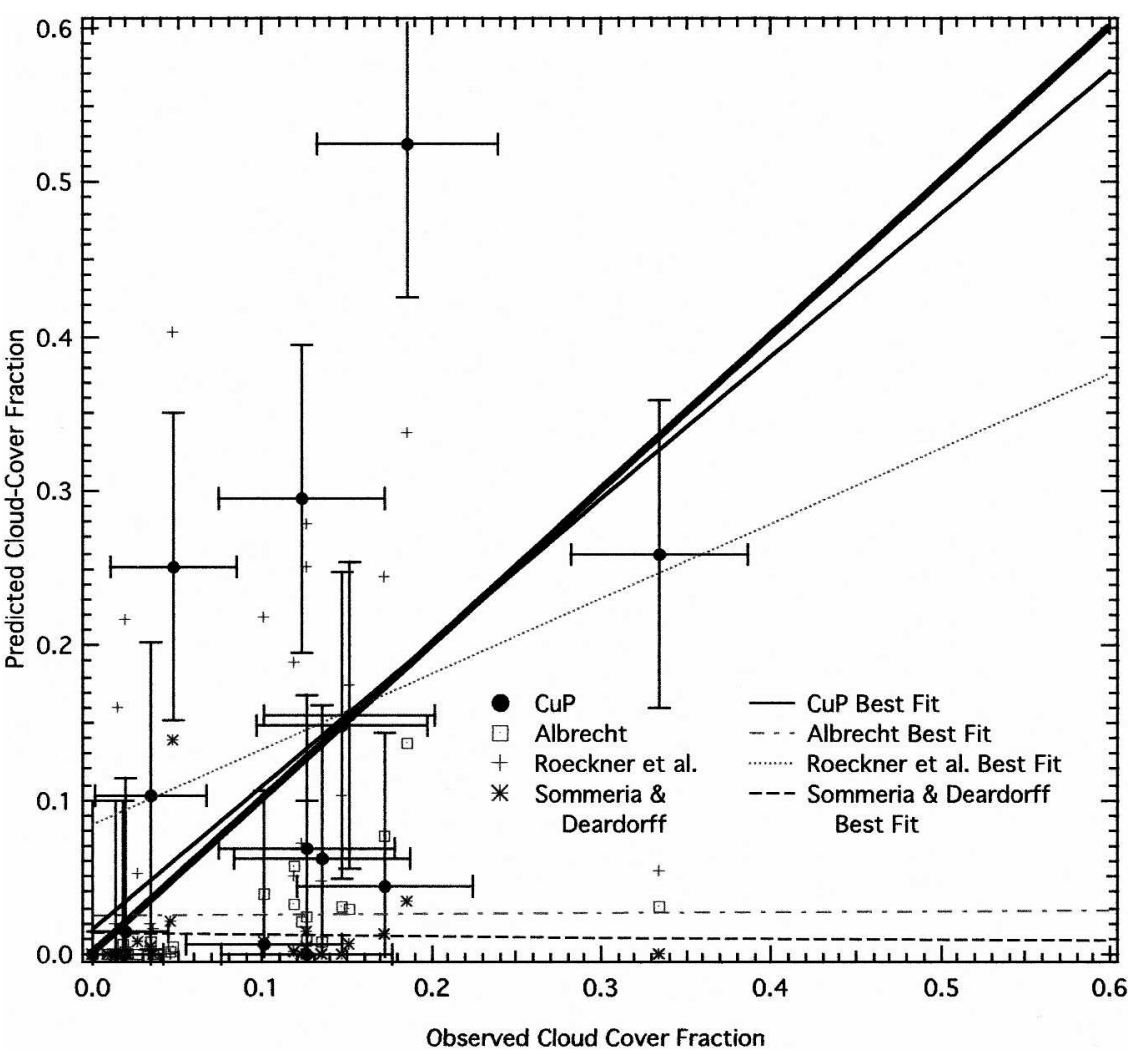

FIG. 7. CuP predicted cloud-cover fraction vs observed cloud-cover fraction for all BLX96 flights using the CuP scheme (dots), and the methods of Albrecht (1981; squares), Roeckner et al. (1996; crosses), and Sommeria and Deardorff (1977; asterisks) vs observed cloud-cover fraction. Lines indicate least squares best fits to the CuP (thin black line), Albrecht (1981; gray dot-dashed line), Roeckner et al. (1996; dotted line), and Sommeria and Deardorff (1977; black dashed line) predicted cloud-cover values. Horizontal error bars indicate likely errors in cloud-cover fraction observations; vertical error bars are the calculated average absolute error of the $\mathrm{CuP}$ parameterization. The heavy solid line is the 1:1 line.

associated with either enhanced vertical transport or subsidence induced by the cumuli.

\section{c. Cloud-top and cloud-base height}

There is good agreement between the observed cloud-base height and the cloud-base height predicted by the $\mathrm{CuP}$ scheme (Fig. 8). The cloud-base height range predicted on any given day is not large, and is of the order of 40 to $240 \mathrm{~m}$ during BLX96. The level of agreement found for cloud-base height is not surpris- ing; Stull and Eloranta (1985) found that the value of $z_{\text {LCL }}$ calculated from surface-layer air did a good job predicting the cloud-base height of boundary layer cumuli as precisely observed using lidar. The agreement between the observed cloud-top height and the CuP scheme-predicted mode cloud-top height is not as good. The methodology used to measure the cloud-top height during BLX96 could be responsible for this result. Cloud-top height was logged using two different methods: one by the airborne scientists during the slant soundings and another from the forward-looking video

TABLE 1. Mean absolute error [calculated using (12)] and mean bias in predicted cloud cover for each method. The fit slope and fit intercept were determined using least squares methods. The likely error in measured cloud cover is 0.05 .

\begin{tabular}{lcccc}
\hline \hline & & & Roeckner el al. & Sommeria and \\
& CuP & Albrecht (1981) & $\begin{array}{c}\text { Somb } \\
\text { Deardorff }(1977)\end{array}$ \\
\hline Mean absolute error & 0.07 & 0.08 & 0.09 & 0.09 \\
Mean bias & -0.01 & -0.07 & 0.04 & -0.08 \\
Sample correlation coefficient & 0.57 & 0.01 & 0.32 & -0.02 \\
Fit slope & 0.93 & 0.0060 & 0.49 & -0.0081 \\
Fit intercept & 0.016 & 0.025 & 0.084 & 0.013 \\
\hline
\end{tabular}




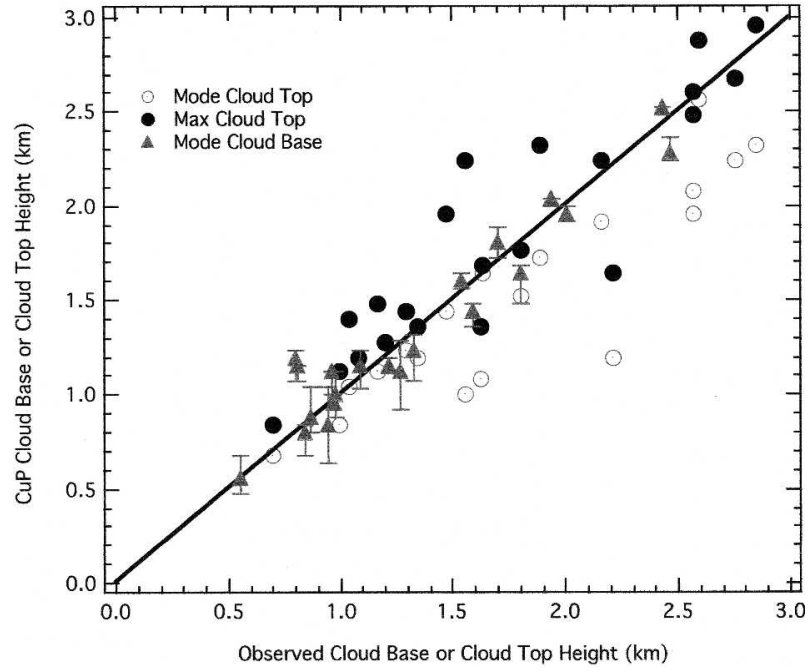

FIG. 8. Plot of the CuP-predicted mode cloud-base height vs observed cloud-base height (triangles), with the CuP-predicted range shown by the vertical error bars, CuP-predicted mode cloud-top height vs observed cloud-top height (open circles), and CuP-predicted maximum cloud-top height vs observed cloud-top height (filled circles). The solid line is the 1:1 line.

camera on the aircraft. Both of these methods focus on the maximum observed cloud-top height, rather than the mean or mode cloud-top height. There is better agreement between the maximum cloud-top height predicted by the CuP scheme and the observed cloud-top height (Fig. 8). An alternative explanation is that $\varepsilon$ is too large; however, the relatively good agreement between the CuP scheme maximum cloud-top height and the observed cloud-top height suggests this is not the case.

For comparison, cloud-base and cloud-top heights were also calculated using the alternate methods of Albrecht (1981), Roeckner et al. (1996), and Sommeria and Deardorff (1977). Estimates of cloud heights were more complicated for these methods because cloud depth is not explicitly predicted. For each of the alternate methods, cloud-base height was defined as the height at which the clouds first form, and maximum cloud-top height was defined as the height at which clouds ceased to exist. The $\mathrm{CuP}$ model seemed to do the best job predicting the cloud-base height (Fig. 9). The methods of Roeckner et al. (1996) and Sommeria and Deardorff (1977) seemed to underestimate the cloudbase height. The method of Albrecht (1981) seems to overestimate the cloud-base height. The CuP model also seems to do the best job predicting the maximum cloud-top height (Fig. 10). Again, the cloud tops shown for the scheme of Roeckner et al. (1996), Sommeria and Deardorff (1977), and Albrecht (1981) are the maximum cloud top. There is more scatter in the cloud-top results of Roeckner et al. (1996), Sommeria and Deardorff (1977), and Albrecht (1981) than for CuPpredicted cloud-top heights.

One advantage of the CuP parameterization is that

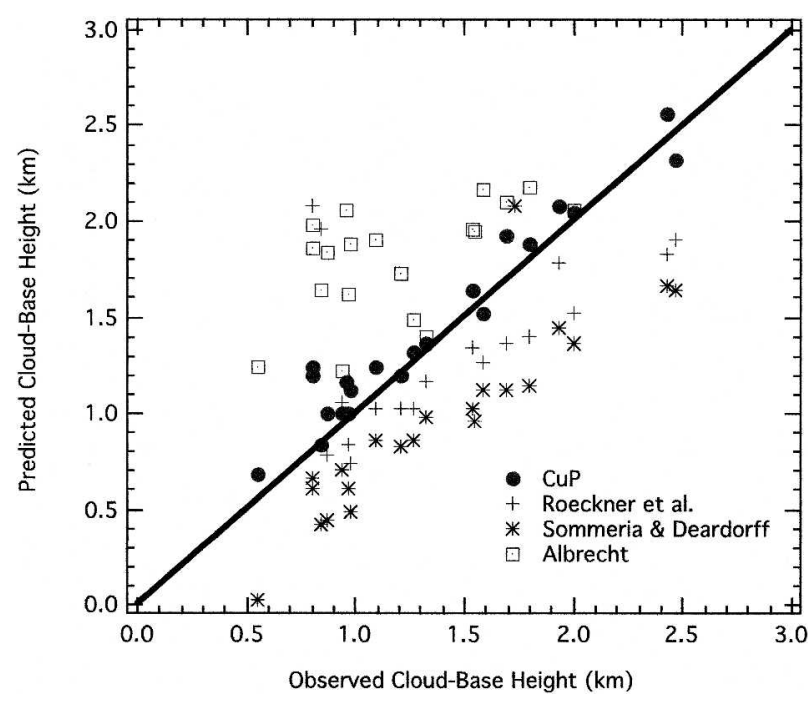

FIG. 9. Plot of CuP (filled circles), Roeckner et al. (1996; crosses), Sommeria and Deardorff (1977; asterisks), and Albrecht (1981; squares) predicted cloud-base height vs observed cloudbase height. The solid line is the 1:1 line.

distributions of cloud-top height and cloud-base height are predicted. Unfortunately, detailed observations of cloud populations were not made during BLX96, so that the actual cloud cover as a function of height cannot be determined. Figure 11 shows an example of the CuP-predicted updraft distributions on 28 July. At the time of the first sounding (1140 LST), the moistest boundary layer parcels are predicted to reach their $z_{\mathrm{LCL}}$ near an altitude of $0.54 \mathrm{~km}$, and most of the rising parcels are saturated at a height of $0.66 \mathrm{~km}$. The tallest predicted clouds reach as high as $0.78 \mathrm{~km}$, but most

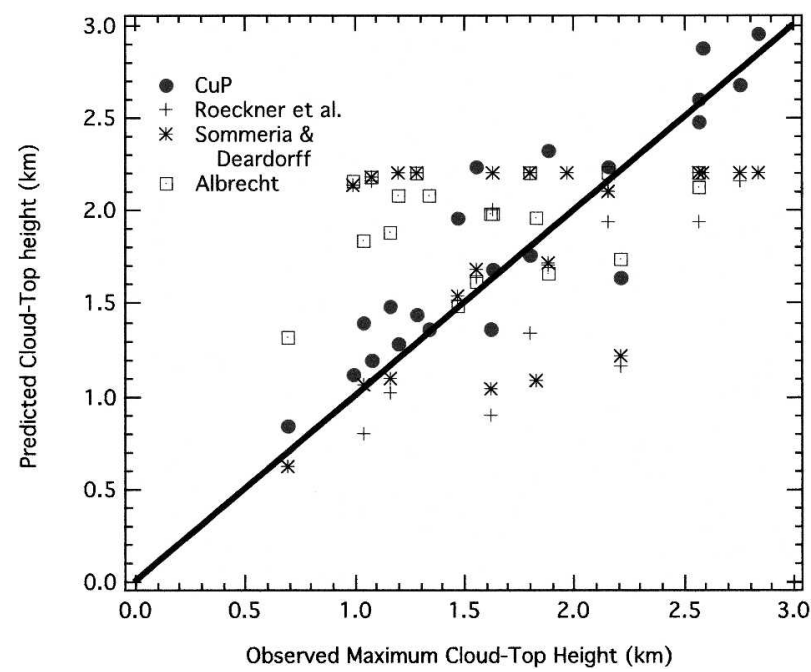

FIG. 10. Plot of CuP (filled circles), Roeckner et al. (1996; crosses), Sommeria and Deardorff (1977; asterisks), and Albrecht (1981; squares) predicted cloud-top height vs observed cloud-top height. The solid line is the 1:1 line. 

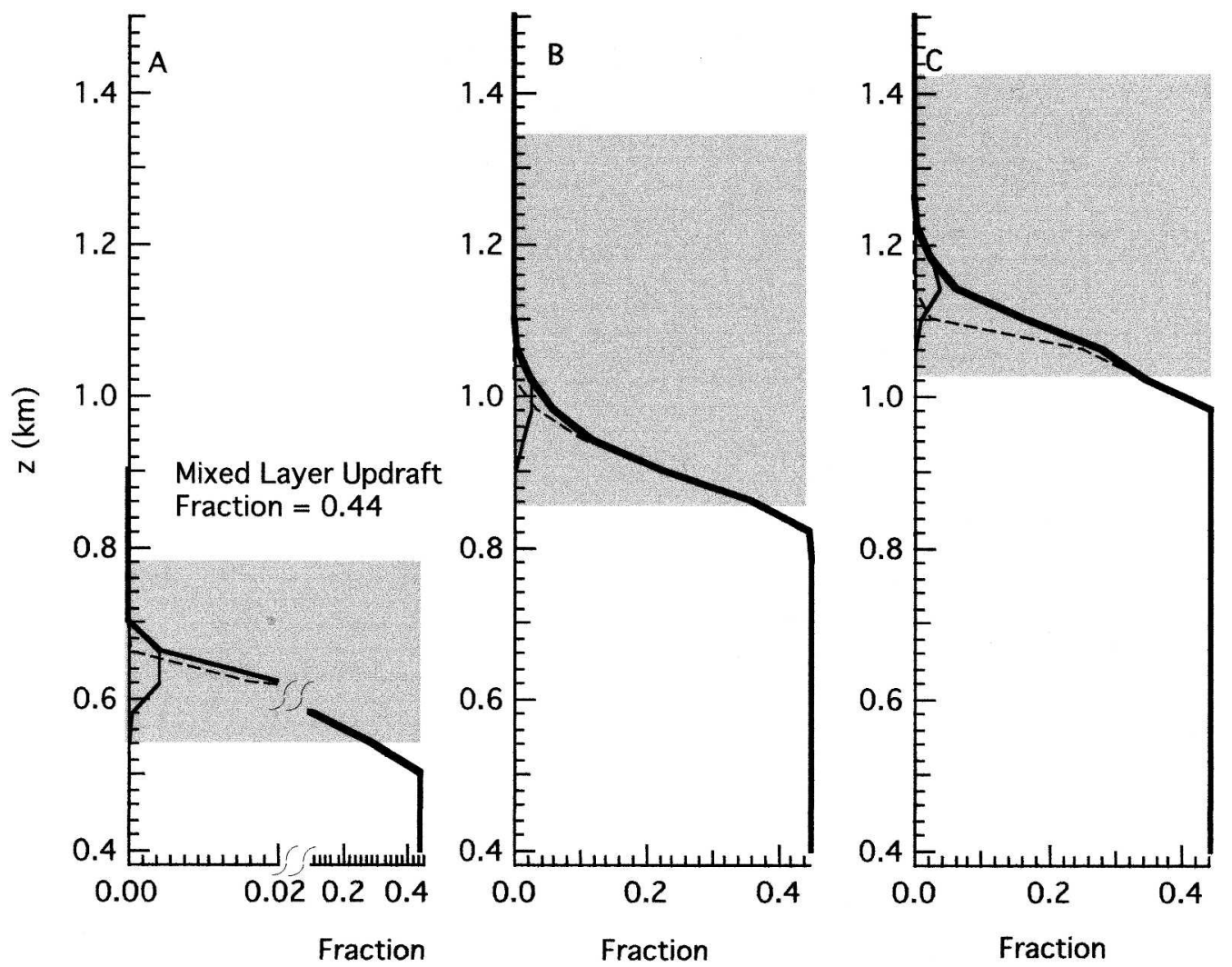

FIG. 11. Total (thick solid line), active cloudy ( $\alpha_{\text {active }}$ ) (thin solid), and clear (dashed line) draft fraction vs height for (a) 1130, (b) 1330, and (c) 1515 LST 27 Jul. Shading marks the entire range of heights with cloudy updrafts predicted by the CuP scheme. Note the change of scale in (a).

cloudy parcels stop before reaching an altitude of 0.68 $\mathrm{km}$. By the time of the second sounding (1330 LST), the mixed layer has dried (parcels begin to reach their $z_{\mathrm{LCL}}$ near an altitude of $0.86 \mathrm{~km})$. The tallest predicted clouds at $1330 \mathrm{LST}$ reach as high as $1.38 \mathrm{~km}$. Between 1330 and 1515 LST, the boundary layer deepens as shown by the predicted tops of the clear thermals. The mixed layer also dries, at 1515 LST a very small number of parcels are predicted to reach their $z_{\mathrm{LCL}}$ near an altitude of $1.1 \mathrm{~km}$. The tallest predicted clouds at 1515 LST reach to $1.46 \mathrm{~km}$, although most only reach $1.3 \mathrm{~km}$. Throughout the day, the fraction of parcels that are rising remains constant, near 0.4. This indicates that although the JPDF changes with time between each leg, the changes are such that the total fraction of rising parcels remains the same.

Several modifications must be made to the scheme before it can be applied in an atmospheric model. The $\mathrm{CuP}$ scheme is sensitive to the inversion height in two ways: first, the jump of $\theta_{v}$ and $r$ at the entrainment zone are used in the JPDF parameterization developed by Berg and Stull (2004), and second, the height of the inversion helps to determine how high the parcels raise. But, the vertical grid spacing in climate models is rather coarse. Grenier and Bretherton (2001) addressed this problem by developing a method in which a GCM can predict a value of the inversion height that is between discreet model levels. Additional modifications would be made to the budget equations for temperature and moisture so that the fair-weather cumuli can interact with their environment.

\section{Conclusions}

A simple parameterization to predict the cloud-cover fraction and the cloud-depth distributions of boundary layer cumuli over heterogeneous land surfaces has been introduced. This new parameterization uses two modules to couple boundary layer cumuli to boundary layer turbulence. The first module represents boundary layer physics using JPDFs of $\theta_{v}$ versus $r$. These distributions are compared to the mean profile of $\theta_{v}$ to determine which parcels rise and which become saturated. The fraction of parcels that become saturated are one component of cloud cover and define the cloud-base height. The second module is a cloud model, which is used to determine the cloud-top height and the lifetime of the boundary layer clouds.

The CuP scheme did a better job predicting cloudbase height and cloud-top height using data collected 
during BLX96 than the three alternative methods of Albrecht (1981), Roeckner et al. (1996), and Sommeria and Deardorff (1977). The agreement between the CuP-observed and -predicted cloud cover is not as good. However, the CuP scheme had a slightly smaller mean error, smaller bias, and higher correlation than three alternative methods. In addition, the CuP method predicts realistic variation of cloud bases and tops, as is observed over real landscapes, and predicts an altitude range near cloud base with both clear and cloud updrafts.

Acknowledgments. This work was completed as part of the lead author's Ph.D. research at the University of British Columbia. The lead author was funded by a University of British Columbia University Graduate Fellowship and the Canadian Climate Research Network through grants from the National Science and Engineering Research Council (NSERC), Meteorological Service of Canada (MSC), and the Canadian Foundation for Climate and Atmospheric Science. Additional support was provided by the Geophysical Disaster Computational Fluid Dynamics Center, and other grants from the National Science and Engineering Research Council and Environment Canada, the Office of Biological and Environmental Research of the U.S. Department of Energy (DE-AC05-76RL01830) as a part of the ARM Program, and the Laboratory Directed Research and Development Program of the U.S. Department of Energy under Contract DE-AC06-76RLO at the Pacific Northwest National Laboratory which is operated for the U.S. Department of Energy by Battelle Memorial Institute. The BLX96 field program was funded by the U.S. National Science Foundation (NSF) under Grant ATM-9411467. E. Santoso and J. Hacker are thanked for their work as airborne scientists during BLX96. The staff and flight crew of the University of Wyoming King Air aircraft (sponsored by NSF) helped to make BLX96 a success. Comments from Dr. Christopher Doran and three anonymous reviewers greatly improved this manuscript.

\section{APPENDIX}

\section{Conditions Used for BOMEX Case}

Holland and Rasmusson (1973) and Nitta and Esbensen (1974) have conducted a large-scale budget

TABLE A1. Mean environment profiles of $p, \theta_{v}$, and $r$ for the BOMEX program during 22-26 Jun 1969.

\begin{tabular}{crrr}
\hline$z(\mathrm{~km})$ & $p(\mathrm{kPa})$ & $\theta_{v}(\mathrm{~K})$ & $r\left(\mathrm{~g} \mathrm{~kg}^{-1}\right)$ \\
\hline 0.0 & 101.5 & 301.9 & 17.3 \\
0.52 & 95.7 & 301.7 & 16.6 \\
1.48 & 84.8 & 304.4 & 10.8 \\
2.00 & 79.7 & 309.0 & 4.2 \\
3.00 & 71.8 & 312.4 & 3.0 \\
4.00 & 64.2 & 315.8 & 1.8 \\
5.00 & 57.3 & 319.3 & 0.6 \\
\hline
\end{tabular}

TABLE A2. Miscellaneous values used for the CuP simulation of the BOMEX case. A subscript sfc indicates a surface value; a subscript ez indicates an entrainment zone value.

\begin{tabular}{lc}
\hline \hline Variable & Value \\
\hline$\frac{z_{i}}{w^{\prime} \theta^{\prime}}{ }_{\mathrm{sfc}}$ & $520 \mathrm{~m}$ \\
$\frac{w^{\prime} \theta^{\prime}}{\mathrm{ez}}$ & $8 \times 10^{-3} \mathrm{~K} \mathrm{~m} \mathrm{~s}^{-1}$ \\
$\frac{w^{\prime} r^{\prime}}{w^{\prime} r_{\mathrm{fc}}^{\prime}}$ & $-1.6 \times 10^{-3} \mathrm{~K} \mathrm{~m} \mathrm{~s}^{-1}$ \\
$\bar{w}^{\prime} \theta_{v \mathrm{sfc}}^{\prime}$ & $5.2 \times 10^{-2} \mathrm{~g} \mathrm{~kg}^{-1} \mathrm{~m} \mathrm{~s}^{-1}$ \\
$w_{*}$ & $4.2 \times 10^{-2} \mathrm{~g} \mathrm{~kg}^{-1} \mathrm{~m} \mathrm{~s}^{-1}$ \\
$\theta_{*}$ & $1.8 \times 10^{-2} \mathrm{~K} \mathrm{~m} \mathrm{~s}^{-1}$ \\
$r_{*}$ & $0.67 \mathrm{~m} \mathrm{~s}^{-1}$ \\
$t_{*}$ & $0.012 \mathrm{~K}^{-1}$ \\
\hline
\end{tabular}

study for phase 3 of BOMEX (22 to 30 June 1969) over the ocean at $55^{\circ} \mathrm{N}, 15^{\circ} \mathrm{W}$. From 22 to 26 June the area was covered with nonprecipitating cumuli. For this case, mean profiles from the R.V. Oceanographer is used (Table A1). Other key variables are listed in Table A2. Surface fluxes were measured near the BOMEX ship. Entrainment-zone fluxes were obtained from the Global Energy and Water Cycle Experiment (GEWEX) Cloud System Study (GCSS) LES model intercomparison (Siebesma et al. 2003). The value of $r_{*}$ was defined using the methods suggested in Berg (2002), and computed as

$$
r_{*}=\left[\frac{\overline{w^{\prime} r_{s}^{\prime}}\left(1-z / z_{i}\right)}{w_{*}}+\frac{\overline{w^{\prime} r^{\prime}}{ }_{z_{i}}\left(z / z_{i}\right)}{w_{*}}\right],
$$

where $\overline{w^{\prime} r^{\prime}}{ }_{s}$ is the surface moisture flux, $\overline{w^{\prime} r^{\prime}} z_{i}$ is the moisture flux at the mixed-layer top, and $z_{i}$ is the height of the mixed layer.

\section{REFERENCES}

Albrecht, B. A., 1979: A model of the thermodynamic structure of trade-wind boundary layer. Part II: Applications. J. Atmos. Sci., 36, 90-98.

- 1981: Parameterization of trade-cumulus cloud amounts. $J$. Atmos. Sci., 38, 97-105.

Barnes, G. M., J. C. Frankhauser, and W. D. Browning, 1996: Evolution of the vertical mass flux diagnosed net lateral mixing in isolated convective clouds. Mon. Wea. Rev., 124, 27642784.

Berg, L. K., 2002: A simple parameterization coupling the convective daytime boundary layer and fair-weather cumuli. $\mathrm{Ph}$.D. dissertation, University of British Columbia, Vancouver, BC, Canada, $166 \mathrm{pp}$

_ and R. B. Stull, 2002: Accuracy of point and line measures of boundary layer cloud amount. J. Appl. Meteor., 41, 640650 .

— , and — 2004: Parameterization of joint frequency distributions of potential temperature and water vapor mixing ratio in the daytime convective boundary layer. J. Atmos. Sci., 61, 813-828.

-, - E. Santoso, and J. P. Hacker, 1997: Boundary Layer Experiment-1996, Airborne Scientist Flight Log. Boundary Layer Technical Report 97-1,116 pp. [Available from Roland Stull, Atmospheric Science Programme, Dept. of Earth and 
Ocean Sciences, UBC, 6339 Stores Rd. Vancouver, BC V6T 1Z4, Canada.]

Betts, A. K., 1973: Non-precipitating cumulus convection and its parameterization. Quart. J. Roy. Meteor. Soc., 99, 178-196.

_ 1975: Parametric interpretation of trade-wind cumulus budget studies. J. Atmos. Sci., 32, 1934-1945.

__ 1976: Modeling subcloud layer structure and interaction with a shallow cumulus layer. J. Atmos. Sci., 33, 2363-2382.

Bony, S., and K. A. Emanuel, 2001: A parameterization of the cloudiness associated with cumulus convection; Evaluation using TOGA COARE data. J. Atmos. Sci., 58, 3158-3183.

Bretherton, C. S., 1993: Understanding Albrecht's model of trade cumulus cloud fields. J. Atmos. Sci., 50, 2264-2283.

_ J. J. R. McCaa, and H. Grenier, 2004: A new parameterization for shallow cumulus convection and its application to marine subtropical cloud-topped boundary layers. Part I: Description and 1D results. Mon. Wea. Rev., 132, 864-882.

Charney, J. G., R. Fjortoft, and J. von Neuman, 1950: Numerical integration of the barotropic vorticity equation. Tellus, 2, 237-254.

Cheinet, S., 2003: A multiple mass-flux parameterization for the surface-generated convection. Part I: Dry plumes. J. Atmos. Sci., 60, 2313-2327.

Cuijpers, J. W. M., and P. Bechtold, 1995: A simple parameterization of cloud water related variables for use in boundary layer models. J. Atmos. Sci., 52, 2486-2490.

Delnore, V. E., 1972: The diurnal variation of the temperature structure and some aspects of heat transfer at the BOMEX fixed stations. J. Phys. Oceanogr., 2, 239-247.

Ek, M., and L. Mahrt, 1991: A formulation for boundary-layer cloud cover. Ann. Geophys., 9, 716-724.

Grant, A. L. M., and A. R. Brown, 1999: A similarity hypothesis for shallow-cumulus transports. Quart. J. Roy. Meteor. Soc., 125, 1913-1936.

Grenier, H., and C. S. Bretherton, 2001: A moist PBL parameterization for large-scale models and its application to subtropical cloud-topped marine boundary layers. Mon. Wea. Rev., 129, 357-377.

Haiden, T., 1996: Generalization of Albrecht's cumulus cloud amount parameterization. J. Atmos. Sci., 53, 3164-3167.

Holland, J. Z., and E. M. Rasmusson, 1973: Measurements of atmospheric mass, energy and momentum budgets over a 500-kilometer square of tropical ocean. Mon. Wea. Rev., 101, $44-55$.

Lappen, C.-L., and D. A. Randall, 2001: Toward a unified parameterization of the boundary layer and moist convection. Part I: A new type of mass-flux model. J. Atmos. Sci., 58, 20212036.

Lock, A. P., A. R. Brown, M. R. Bush, G. M. Martin, and R. N. B. Smith, 2000: A new boundary layer mixing scheme. Part I: Scheme description and single-column model tests. Mon. Wea. Rev., 128, 3187-3199.

Malkus, J. S., 1954: Some results of a trade-cumulus cloud investigation. J. Meteor., 11, 220-237.

— 1958: On the structure of the trade wind moist layer. Pap. Phys. Oceanogr. Meteor., 13.

Mellor, G., 1977: The Gaussian cloud model relations. J. Atmos. Sci., 34, 356-358.

Neggers, R. A. J., A. P. Siebesma, and H. J. J. Jonker, 2002: A multiparcel model for shallow cumulus convection. J. Atmos. Sci., 59, 1655-1668.

Nitta, T., 1975: Observational determination of cloud mass flux distributions. J. Atmos. Sci., 32, 73-91.
— using BOMEX data. Mon. Wea. Rev., 102, 17-28.

Richardson, R. F., 1922: Weather Prediction by Numerical Process. Cambridge University Press, 236 pp. (Reprint, 1965, Dover Publications.)

Roeckner, E., and Coauthors, 1996: The atmospheric general circulation model ECHAM-4: Model description and simulation of present-day climate. Tech. Rep. 218, Max-PlanckInstitut fur Meteorologie, $90 \mathrm{pp}$.

Schrieber, K., R. Stull, and O. Zhang, 1996: Distributions of surface layer buoyancy versus lifted condensation level over a heterogeneous land surface. J. Atmos. Sci., 53, 1086-1107.

Siebesma, A. P., and J. W. M. Cuijpers, 1995: Evaluation of parametric assumptions for shallow cumulus convection. $J$. Atmos. Sci., 52, 650-666.

_ , and A. A. M. Holtslag, 1996: Model impacts of entrainment and detrainment rates in shallow cumulus convection. $J$. Atmos. Sci., 53, 2354-2364.

—, and Coauthors, 2003: A large-eddy simulation intercomparison study of shallow cumulus convection. J. Atmos. Sci., 60, 1201-1219.

Simpson, J., and V. Wiggert, 1969: Models of precipitating cumulus towers. Mon. Wea. Rev., 97, 471-489.

Slingo, J. M., 1987: The development and verification of a cloud prediction scheme for the ECMWF model. Quart. J. Roy. Meteor. Soc., 113, 899-927.

Smith, R. N. B., 1990: A scheme for predicting layer clouds and their water content in a GCM. Quart. J. Roy. Meteor. Soc., 116, 435-460.

Sommeria, G., and J. W. Deardorff, 1977: Subgrid-scale condensation in models of non-precipitating clouds. J. Atmos. Sci., 34, 344-355.

Stokes, G. M., and S. E. Schwartz, 1994: The Atmospheric Radiation Measurement (ARM) Program: Programmatic background and design of the cloud and radiation test bed. Bull. Amer. Meteor. Soc., 75, 1201-1222.

Stull, R. B., 1985: A fair-weather cumulus cloud classification scheme for mixed layer studies. J. Climate Appl. Meteor, 24, $49-56$.

—, and E. Eloranta, 1985: A case study of the accuracy of routine, fair-weather cloud-base reports. Natl. Wea. Dig., 10, $19-24$.

_ E. Santoso, L. Berg, and J. Hacker, 1997: Boundary Layer Experiment 1996 (BLX96). Bull. Amer. Meteor. Soc, 78, $1149-1158$

Sundqvist, H., 1978: A parameterization scheme for non-convective condensation including prediction of cloud water content. Quart. J. Roy. Meteor. Soc., 104, 677-690.

von Salzen, K., and N. A. McFarlane, 2002: Parameterization of bulk effects of lateral and cloud-top entrainment in transient shallow cumulus clouds. J. Atmos. Sci., 59, 1405-1430.

Wetzel, P. J., 1990: A simple parcel method for prediction of cumulus onset and area-averaged cloud amount over heterogeneous land surfaces. J. Appl. Meteor., 29, 516-523.

Wang, S., and B. A. Albrecht, 1986: Stratocumulus model with an internal circulation. J. Atmos. Sci., 43, 2374-2391.

_ and - 1990: A mean gradient of the convective boundary layer. J. Atmos. Sci., 47, 126-138.

Wyngaard, J. C., and C.-H. Moeng, 1992: Parameterization turbulent diffusion through the joint probability density. Bound.-Layer Meteor., 60, 1-13.

Xu, K.-M., and S. K. Krueger, 1991: Evaluation of cloudiness parameterizations using a cumulus ensemble model. Mon. Wea. Rev., 119, 342-367. 